\title{
The Study of Load Distribution for Combination Bearing in Wellbore Trajectory Control Tool
}

\author{
D. Feng, Z.W. Liao, H. Zhang, L. Shi, C.Y. Xia, S.Z. Wei \\ The Department of Mechanical Engineering \\ Yangtze University \\ Jingzhou Hubei, China \\ Hubei Coopreative Innovation Center of Unconventional Oil and Gas \\ Wuhan, Hubei, China
}

\begin{abstract}
In this paper, the load distribution of combination bearing in wellbore trajectory control tool has been carried out the theoretical study, it is concluded the response of combination bearing in pure radial \& axial load bearing. Based on this study, the working state of combination bearing has been simulated using COMSOL for the several coupling system. The result of theoretical study are well agreement with the simulation result, it can be known that the numerical model is right in this paper. This research is a guiding significance to the design of combination bearing in actual engineering problem.
\end{abstract}

Keywords- wellbore trajectory control tool; combination bearing; load distribution; numerical simulation

\section{INTRODUCTION}

Wellbore trajectory control tool is the key technology for the steering drilling. According to the way of working, it can be divided into three categories: static Push-the-Bit, dynamic Push-the-Bit and static Point-the-Bit [1-2]. The Point-the-Bit wellbore trajectory control tool can achieve deflecting mainly by adjusting eccentric ring between the combination bearing and cantilever bearing. It is main role of cantilever bearing to support the spindle and prevent the upper bent of spindle. The main role of combination bearing is promoting the spindle bottom to steering drilling [3].The working principle diagram is shown in Fig. 1.

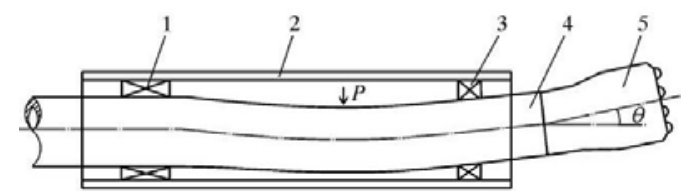

1-support bearing 2-shell of tool 3-combination bearing 4-rotating spindle 5-bit

FIGURE I. THE WORKING PRINCIPLE DIAGRAM OF WELLBORE TRAJECTORY CONTROL TOOL.

Combination bearing consists of a spherical roller bearing and two thrust self-aligning bearings. The thrust self-aligning bearings are symmetrically arranged about spherical roller bearing. On one hand, the purpose of this installation is to balance the load in all directions of tool. On the other hand, it is to provide a fulcrum for wellbore trajectory control tool to facilitate deflection. In the processes of drilling, the working state of the bearing will change with the bending of the spindle[4]. The study of load distribution for combination bearing would be significant for the normal drilling.

\section{THE THEORY STUDY OF LOAD DISTRIBUTION FOR COMBINATION BEARING}

\section{A. The Load Distribution under Pure Radial Load}

There are two kinds of limit state of bearing movement(Fig. 2). In the state Fig. 2(a), radial load action line goes through the centre of rolling elements. The number of rolling element which contact with raceway at this time, it can only be an odd number and this state is called the "odd press" state. In the state Fig. 2(b), the load just acts on the bisector of angle between two rolling elements. The number of rolling element which contact with raceway at this time, it can only be an even number and this state is called the "even press" state [5].

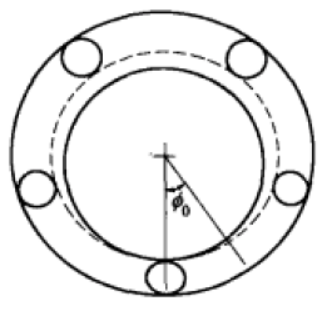

(a) "odd press" state

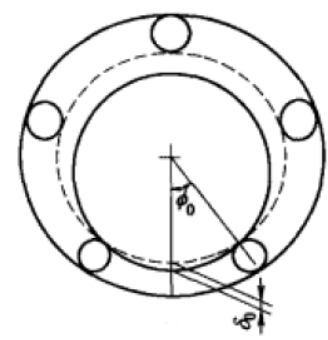

(b) "even press" state
FIGURE II. TWO KINDS OF LIMIT STATE OF ROLLING ELEMENTS MOVEMENT.

According to classical bearing analysis theory, the theory of rigid ring is adopted [6]. In Fig. 3, the inner and outer circle of bearing are assumed that produce relative displacement $\delta_{\mathrm{r}}$ under the radial load $\mathrm{F}_{\mathrm{r}}$. The displacement component in any position angle $\varphi$ is:

$$
\delta_{\phi}=\delta_{\mathrm{r}} \cos \phi
$$




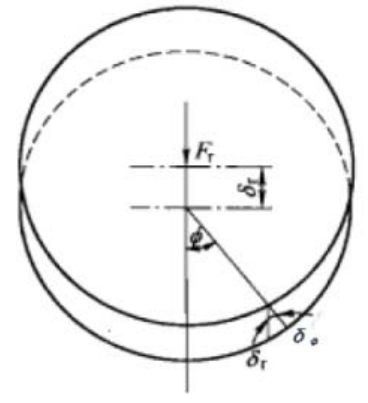

FIGURE III. THE RADIAL DISPLACEMENT COMPONENT.

From Fig. 4, the normal component of radial displacement $\delta_{\mathrm{r} \varphi}$ is:

$$
\delta_{\mathrm{e} \phi}=\delta_{r \phi} \cos \alpha_{e}=\delta_{\mathrm{r}} \cos \phi \cos \alpha_{e}
$$
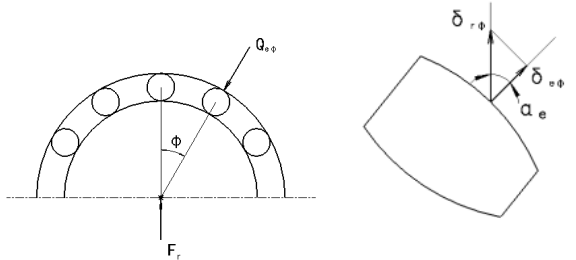

FIGURE IV. THE NORMAL CONTACT DEFORMATION.

And from the relation between load and deformation[7], this can be got :

$$
Q_{e \phi}=K \delta_{e \phi}{ }^{\varepsilon}
$$

Here, $\mathrm{K}$ is the stiffness coefficient, and $\mathrm{K}=2.89 \times 10^{4} 1^{0.82} \mathrm{D}_{\mathrm{w}}{ }^{0.11}$.In this formula, 1 is the length of rolling element; $D_{w}$ is the equivalent diameter of rolling element; the value of $\varepsilon$ is $10 / 9$ here. From equation (2) and equation (3), the relation between the normal load of rolling element $\mathrm{Q}_{\mathrm{e} \varphi}$ in the position angle $\varphi$ and the biggest normal load of rolling element $\mathrm{Q}_{\mathrm{e}}$ is as follows:

$$
Q_{e \phi}=Q_{e}(\cos \phi)^{10 / 9}
$$

As only when $\phi$ ranges from $-\frac{\pi}{2}$ to $\frac{\pi}{2}, \delta_{\mathrm{r} \varphi} \geq 0$.So under the condition of the contact, the equilibrium equation can be established as follows:

$$
\begin{gathered}
\mathrm{F}_{\mathrm{r}}=\sum_{\phi \geq-\pi / 2}^{\phi \leq \pi / 2} \mathrm{Q}_{\mathrm{e} \phi} \cos \alpha_{\mathrm{e}} \cos \phi=\mathrm{Q}_{\mathrm{e}} \mathrm{ZJ} \mathrm{J}_{\mathrm{ra}} \cos \alpha_{\mathrm{e}} \\
\mathrm{Q}_{e}=\frac{F_{\mathrm{r}}}{Z J_{r a} \cos \alpha_{e}}
\end{gathered}
$$

Where, the number of the rolling elements is $\mathrm{Z}$ and $\mathrm{J}_{\mathrm{ra}}$ is the radial load distribution coefficient under "odd press" state its value is:

$$
J_{\mathrm{ra}}=\frac{1}{Z}\left\{1+2 \sum_{\phi=2 \pi / Z}^{\leq \pi / 2}(\cos \phi)^{19 / 9}\right\}
$$

The equilibrium equation under "even press" state is as follows:

$$
\begin{gathered}
\mathrm{F}_{\mathrm{r}}=\sum_{\phi \geq-\pi / 2}^{\phi \leq \pi / 2} \mathrm{Q}_{\mathrm{e} \phi} \cos \phi=\mathrm{Q}_{\mathrm{e}} \mathrm{ZJ}_{\mathrm{rb}} \cos \alpha_{\mathrm{e}} \\
Q_{e}=\frac{F_{\mathrm{r}}}{Z J_{r b} \cos \alpha_{e}} \\
J_{\mathrm{rb}}=\frac{2}{Z} \sum_{\phi=\pi / Z}^{\leq \pi / 2}(\cos \phi)^{19 / 9}
\end{gathered}
$$

In "even press" state, the actual maximum load appears in a pair of rolling elements which is the closest distance to the load line. Its value is:

$$
Q_{\mathrm{e}}{ }^{\prime}=Q_{e}\left[\cos \left(\frac{\pi}{z}\right)\right]^{10 / 9}
$$

\section{B. The Load Distribution under Pure Axial Load}

Under the action of pure axial load, inner and outer circle of bearing will produce a relative displacement $\delta_{\mathrm{a}}$, (Fig. 5). The rolling elements' contact load is $\mathrm{Q}_{\mathrm{e}}$. The normal contact deformation is $\delta_{e}$, and the contact angle is $\alpha_{e}$.
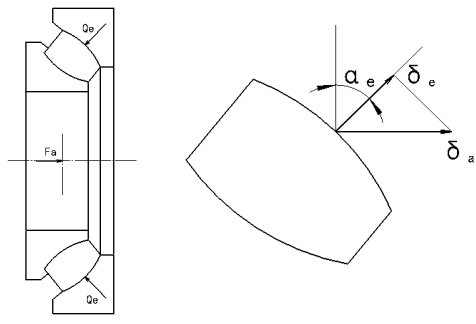

FIGURE V. THE ACTION OF AXIAL LOAD.

As the normal contact deformation which caused by axial displacement is:

$$
\delta_{\mathrm{e}}=\delta_{\mathrm{a}} \sin \alpha_{\mathrm{e}}
$$

Therefore, the contact load of rolling element can be obtained as follows:

$$
\mathrm{Q}_{\mathrm{e}}=\mathrm{K} \delta_{\mathrm{e}}{ }^{10 / 9}=\mathrm{K} \delta_{\mathrm{a}}{ }^{10 / 9}\left(\sin \alpha_{\mathrm{e}}\right)^{10 / 9}
$$

When the number of bearing's rolling elements is $Z$, the equation is:

$$
F_{a}-Z K \delta_{a}^{10 / 9}\left(\sin \alpha_{e}\right)^{19 / 9}=0
$$

So axial displacement is obtained as follows:

$$
\delta_{\mathrm{a}}=\left(\frac{F_{a}}{Z K\left(\sin \alpha_{e}\right)^{19 / 9}}\right)^{9 / 10}
$$

\section{THE FINITE ELEMENT ANALYSIS (FEA) OF COMPOSITE BEARING}

There are two kinds of working state when wellbore trajectory control tool is under normal working condition. In 
normal drilling, spindle only sustains the axial bit pressure. In steering drilling, on one hand, the spindle sustains the axial bit pressure. On the other hand, it also sustains the radial force which is applied by eccentric mechanism. So during the FEA, two cases will be divided.

\section{A. Modeling, Material Selection and Meshing of Combination Bearing}

The Solidworks software is used to establish the three-dimensional model of bearing [8-9]. Then we use the multi-physics field analysis software COMSOL for analyzing combination bearing's load situation in two kinds of conditions.

In the operation of wellbore trajectory control tool, rolling elements are demanded having good mechanical property. For this reason, bearing steel is selected as the material of this bearing[10-11].The manner of free mesh is adopt meshing combination bearing's grid.

\section{B. Adding Boundary Conditions}

In this article, the three bearing race need to be added fixed constraint. In addition, under normal working condition, the two thrust self-aligning bearings' race need to be added axial pre-tightening force of $1089 \mathrm{~N}$.

In the condition of steering drilling, through the mechanical analysis of the spindle, the shaft circle of spherical roller bearing and the inside of two gaskets need to be added radial force of $12733 \mathrm{~N}$. At the same time, the both ends of bearing should also be added the pre-stressing force of $1089 \mathrm{~N}$.

\section{Results and Analysis}

(1) The results and analysis of normal drilling

For the response of bearing load to the boundary conditions, through the above pre-treatment and solving, the stress and displacement diagrams of combination bearing's YZ plane during normal drilling are got. They are shown in Fig. 6 7.

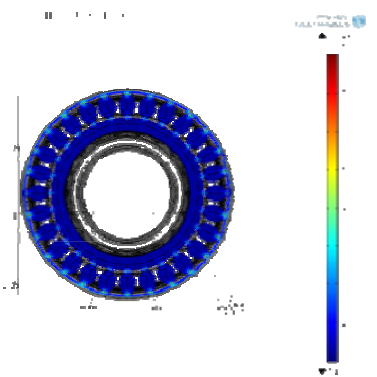

FIGURE VI. STRESS DIAGRAM OF YZ PLANE.

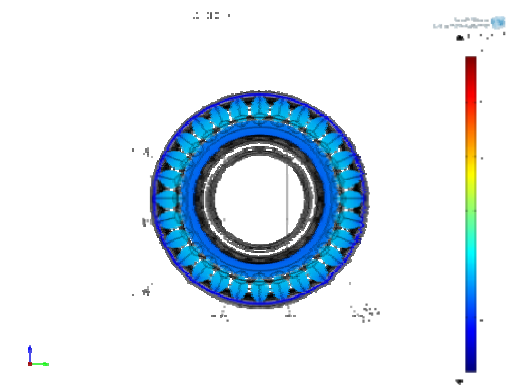

FIGURE VII. DISPLACEMENT DIAGRAM OF YZ PLANE.

From the two diagrams, we can see under the effect of pre-stressing force. The stress mainly is on the two thrust self-aligning bearings. In addition, the displacement of the thrust spherical roller bearing race's inside is most obvious and. From the diagram, we also can see the load is born by all rolling elements evenly under the effect of pre-tightening force. It's consistent with the result in 2.2 under pure axial loading and the stress mainly concentrated in the contact area between rolling element and raceway.

(2) The results and analysis of steering drilling

When steering drilling, the stress and displacement diagram of combination bearing in $\mathrm{YZ}$ plane and $\mathrm{XY}$ plane is shown in Fig. 8 9.

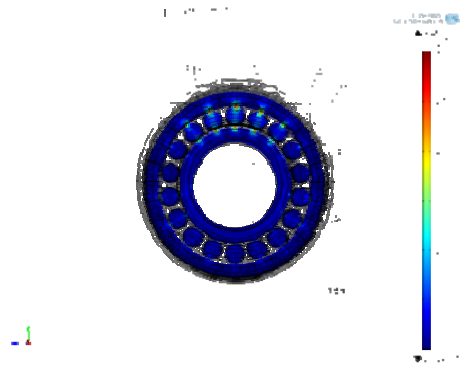

FIGURE VIII. STRESS DIAGRAM OF YZ PLANE.

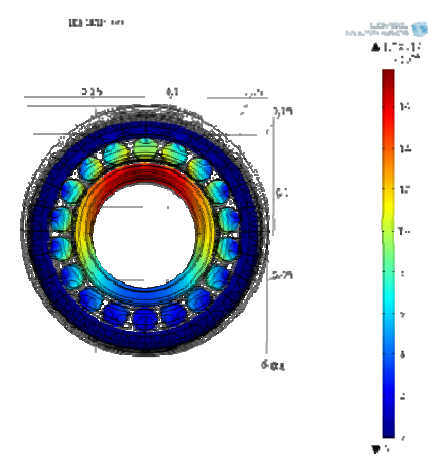

FIGURE IX. DISPLACEMENT DIAGRAM OF YZ PLANE.

From the diagrams, we can see this produces large stress and displacement on the radial load line of the rolling element and raceway contact parts, when the outer ring is fixed. The stress away from the area will gradually decrease.

From the analysis results, the load response of bearing mainly concentrated on the contact area of rolling element and 
raceway. And under the action of radial load, the upper circle rolling element carrying is larger, while the under circle rolling element is almost not affected by load. In addition, we can see rolling element load distribution has the characteristics of " be big in the middle and small at both ends". As when steering drilling, the radial force is greater than the axial force. Now the influence of the axial force to the rolling element load response is very small, the action of pure radial load can be thought to be condition of steering drilling. So this is consistent with the theoretical study result in 2.1 under pure radial loading.

\section{CONCLUSION}

In this paper, through the comparison of theoretical study results and FEA results, the following conclusions can be obtain:

(1) The load of combination bearing is evenly taken by the rolling element in normal drilling. Most of the pre-tightening force is sustained by thrust self-aligning bearings while the spherical roller bearing is not affected by load.

(2) When the combination bearing is in steering drilling, the load of rolling element through the action line which is in the centre of the bearing is the largest. The load on both sides of bearing is reduced in turn, and the stress is mainly concentrated in the contact part between the rolling elements and raceway.

\section{ACKNOWLEDGEMENT}

This work of the paper was supported by the national natural science foundation of China (51275057), Hubei province natural science foundation of innovation (51275057) and the scientific research fund for the doctoral program of higher education (Doctoral Tutor 20124220110003).

\section{REFERENCES}

[1] Feng Ding, Yuan Yongxin, Li Hanxing, et al., The present situation and development trend of the well track control. Journal of petroleum machinery, 1,pp. 70-73,2011.

[2] Su Yinao, Dou Xiurong, Wang Jiajin., The characteristics and typical structure of rotary steering drilling system. Oil drilling technology,4,pp. 5-7 + 83, 2003 .

[3] Fu Tianming., Study of development and application of Geo-Pilot rotary steering drilling system. Oil field machinery, 5,pp. 77-80,2014.

[4] Zhou Qin, Liu Baolin, Li Ying., The research on the effects of bending of rotary steering tool spindle to the cantilever bearing. Journal of petroleum machinery, 10, pp.14-17 + 93-94, 2010.

[5] Luo Tianyu, Luo Jiwei., Running vibration of rolling bearings. Journal of bearing, 11,pp.5-7,2007.

[6] Luo Jiwei., The force analysis and its progress of the rolling bearing. Journal of bearing, 09,pp. 28-31+47-34,2001,.

[7] Harris TA., Rolling Bearing Analysis, John Wiley \& Sons Inc: New York, pp.78, 1984 .

[8] Chen Shangshu. Research and development of the CAD system for rolling bearing based on SolidWorks [D]. China university of geosciences (Beijing), 2013.

[9] Ouyang Huabing, Ling feng, Wang Jianping. The CAD and three-dimensional graphical modeling of rolling bearing based on the SolidWorks software. Journal of light industrial machinery, 06,pp. 45 47,2007.

[10] D. Bombač, M. Terčelj, I. Peruš, P. Fajfar. The progress of degradation on the bearing surfaces of nitrided dies for aluminium hot extrusion with two different relative lengths of bearing surface. Wear, 2,pp.30
34,2013 .

[11] S. M. Muzakkir, K. P. Lijesh, Harish Hirani. Tribological failure analysis of a heavily-loaded slow speed hybrid journal bearing. Engineering Failure Analysis, 2,pp.40,2014. 